Annales Geophysicae (2001) 19: 953-963 (C) European Geophysical Society 2001

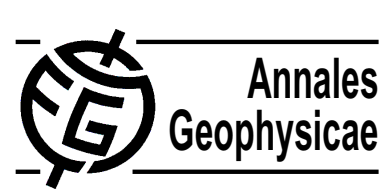

\title{
Mixing processes in a tropopause folding observed by a network of ST radar and lidar
}

\author{
F. Bertin ${ }^{1}$, B. Campistron ${ }^{2}$, J. L. Caccia ${ }^{3}$, and R. Wilson ${ }^{4}$ \\ ${ }^{1}$ CETP, 4 Avenue de Neptune, 94107 Saint Maur-des-fossés, France \\ ${ }^{2}$ C.R.A., 65300 Lannemezan, France \\ ${ }^{3}$ LSEET, BP 132, 83957 La Garde, France \\ ${ }^{4}$ S. A., BP 102, 4 Place Jussieu, 75004 Paris, France
}

Received: 17 August 2000 - Revised: 19 February 2001 - Accepted: 22 March 2001

\begin{abstract}
A campaign devoted to stratosphere-troposphere exchange mechanisms studies has been held on 4-5 March 1995, during a tropopause folding passage over western $\mathrm{Eu}-$ rope. The observational network included $1 \mathrm{UHF}$ and $3 \mathrm{VHF}$ radar, 1 temperature lidar, and 1 ozone lidar, deployed in the south of France. The fold is associated with a strong quasi meridional jet stream running along the west side of an upper level trough forming a potential vorticity $(P V)$ anomaly. During this campaign, the $P V$ anomaly is advected eastwards without major deformations, with an average velocity of about $30 \mathrm{~km}$ per hour. Therefore, a frozen field hypothesis has been used in order to compare the results obtained in the different sites of the network. Under this hypothesis, the same structures associated with the anomaly are observed by each radar or lidar, at the same time relative to this anomaly. The fold is put into evidence by the ozone lidar of the network and by the VHF radars when computing the aspect ratio. The turbulent activity observed by the OHP VHF radar and by the high resolution UHF PROUST radar (30 $\mathrm{m}$ altitude resolution) is concentrated in the wind shear regions generated by the jet stream above and below its axis. In the lower level wind shear, turbulent layers are detected within the fold and across its anticyclonic boundary, thus allowing turbulent exchanges with the tropospheric air masses. A large area of aspect ratio greater than 3 is observed in the troposphere during more than ten hours after the passage of the fold by the VHF radars. This particular signature is tentatively analyzed as the progressive dilution of air masses of stratospheric origin extruded from the fold by the turbulent processes. In the upper level wind shears, turbulent layers parallel to the wind isotachs are observed, whose thickness is often smaller than $100 \mathrm{~m}$ and are separated by non turbulent regions. A good correlation is found between the spatiotemporal evolution of these turbulent structures observed by the PROUST radar, and the stability structures observed at the same relative time by the temperature lidar. In addition the same turbulent structures are observed to be parallel to
\end{abstract}

Correspondence to: F. Bertin (francois.bertin2@wanadoo.fr) the iso-phase lines of the wind fluctuations, observed at the same relative time by the Lannemezan radar. These characteristics are compatible with the presence of unstable inertiagravity waves, generated by the jet stream while the turbulent layers could be the signature of their saturation processes.

Key words. Atmospheric composition and structure (evolution of the atmosphere) - Meteorology and atmospheric dynamics (middle atmosphere dynamics; turbulence)

\section{Introduction}

Several campaigns have been organized in France for three years (1993-1995) in order to better characterize the atmospheric exchange mechanisms that take place across the tropopause level during tropopause folding (TF) and cutoff lows (COL) events at the regional scale. The experimental network included a set of ST radar and lidar, located in the South of France. The concept of Intensive Observation Period (IOP) was used, in conjunction with the activation of the network when a relevant COL or TF was forecasted over the network area by the operational models (ARPEGE and ECMWF). In this network, three VHF radar and one UHF (961 MHz) radar were involved, the characteristics and location of these radar are summarized in Table 1. The network also included one UV DIAL ozone lidar and one Raman temperature lidar, located at the Haute Provence Observatory (OHP). Their height and time resolution were $400 \mathrm{~m}$ and 10 minutes, respectively.

Three papers about the results obtained during these campaigns have already been published: the first one (Campistron et al., 1999) studies the aspect sensitivity of VHF radar echoes obtained during the passage of a cutoff low by the Lannemezan radar; the second one (Ravetta et al., 1999) compares the temperature and wind field measurements obtained in the Haute Provence Observatory in a tropopause fold with a mesoscale model; the third one (Caccia et al., 2000) assesses the monitoring of cutoff lows and tropopause folds by 
Table 1. Main characteristics of the network and advection time of the $P V$ anomaly between the different sites

\begin{tabular}{lcccccc}
\hline Radar & Coordinates & $\begin{array}{c}\text { Frequency } \\
(\mathrm{MHz})\end{array}$ & $\begin{array}{c}\text { Mean Power } \\
(\mathrm{W})\end{array}$ & \multicolumn{2}{c}{ Resolution } & $T_{0}$ \\
& Range (m) & Time (min) & (UTC) \\
\hline Lannemezan & $43^{\circ} 08^{\prime} \mathrm{N}, 00^{\circ} 22^{\prime} \mathrm{E}$ & 45 & 800 & 375 & 4 & 04 \\
PROUST & $44^{\circ} 30^{\prime} \mathrm{N}, 02^{\circ} 08^{\prime} \mathrm{E}$ & 961 & 1000 & 30 & 1 & 09 \\
Hte Prov obs & $43^{\circ} 54^{\prime} \mathrm{N}, 05^{\circ} 48^{\prime} \mathrm{E}$ & 72 & 720 & 375 & 4 & 18 \\
Toulon & $43^{\circ} 10^{\prime} \mathrm{N}, 05^{\circ} 55^{\prime} \mathrm{E}$ & 45 & 800 & 375 & 4 & 18 \\
\hline
\end{tabular}

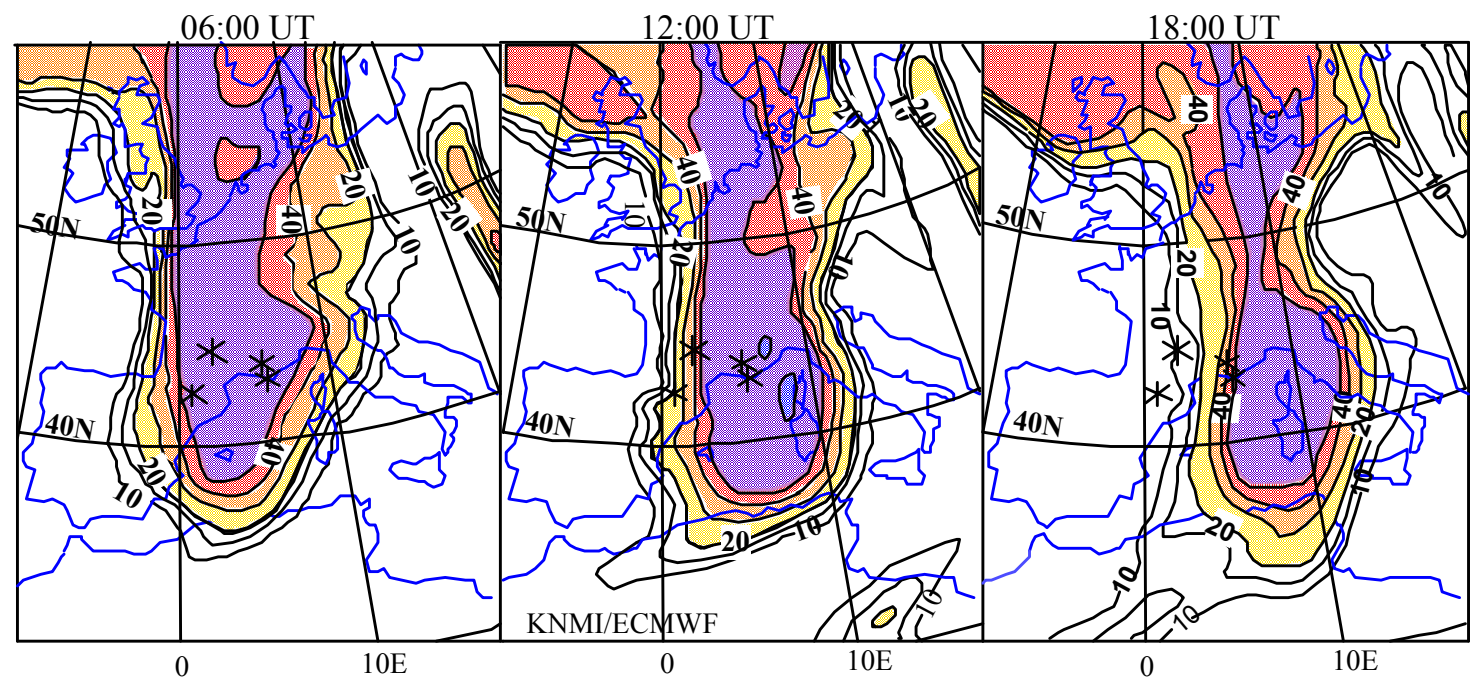

Fig. 1. ECMWF analysis on Saturday, 4 March 1995. Potential vorticity on the $300 \mathrm{hPa}$ isobaric surface at 0600 UT (left), 1200 UT (center) and 1800 UT (right).

the aspect ratio derived from the radar measurements.

The present contribution is aimed to compare during a tropopause fold event the results obtained by the VHF radar, UHF radar, ozone and temperature lidar with the European Center for Medium-Range Weather Forcasting (ECMWF) model outputs, in order to better understand: (i) the physics of the radar measurements, (ii) the mechanisms involved in the turbulence onset along the fold borders and at the tropopause level, possibly giving rise to air mass exchanges between the troposphere and the stratosphere. The main difficulty that arises when comparing the observations obtained by the network is that the same tropopause folding event is successively observed by the different radar sites. The comparison is valid only if the different meteorological fields associated with the fold do not significantly change along their advection. Therefore, the second section of this contribution is devoted to the assessment of the frozen fields hypothesis applied to the fold during its passage over the network. In the third section, the observation of the fold by the ozone lidar is compared with the sigal-to-noise ratio, observed by the OHP radar and with the spatio-temporal evolution of the aspect ratio estimated from the Lannemezan and Toulon VHF radar. In Sect. 4, the turbulent field observed by the high resolution PROUST radar is compared with stability structures detected in the same regions of the fold by the OHP temperature lidar.
In an attempt to tentatively understand the similarity of the structures observed by both instruments, Sect. 5 is devoted to the analysis of the wind fluctuations observed by the Lannemezan radar, in terms of inertia-gravity waves. Finally, in the conclusion, a synthesis of the results obtained is presented and its comparison with previous work is discussed.

\section{Meteorological context and assessment of the frozen fields hypothesis}

On 4 March 1995, the meteorological situation shows the presence of a N-S upper level trough, forming a Potential Vorticity $(P V)$ anomaly, rapidly advected eastward over western Europe without major deformations, as observed in Fig. 1, where the $(P V)$ maps on the $300 \mathrm{hPa}$ surface at 0600, 1200 and 1800 UT, derived from the ECMWF model analysis, clearly indicate a pure eastward advection of the $P V$ anomaly. The use and significance of potential vorticity maps, as well as the $P V$ unit ( $1 P V$ unit $=10^{-6} \mathrm{~m}^{2} \mathrm{~s}^{-1} \mathrm{~K} \mathrm{~kg}^{-1}$ ) are described in Hoskins et al. (1985).

The eastward advection velocity of the anomaly, derived from Fig. 1, is found to be about $30-32 \mathrm{~km} / \mathrm{h}$ at $40^{\circ}$ latitude north. Along the western side of this anomaly, a strong northsouth jet stream is running. An upper level frontogenesis as- 


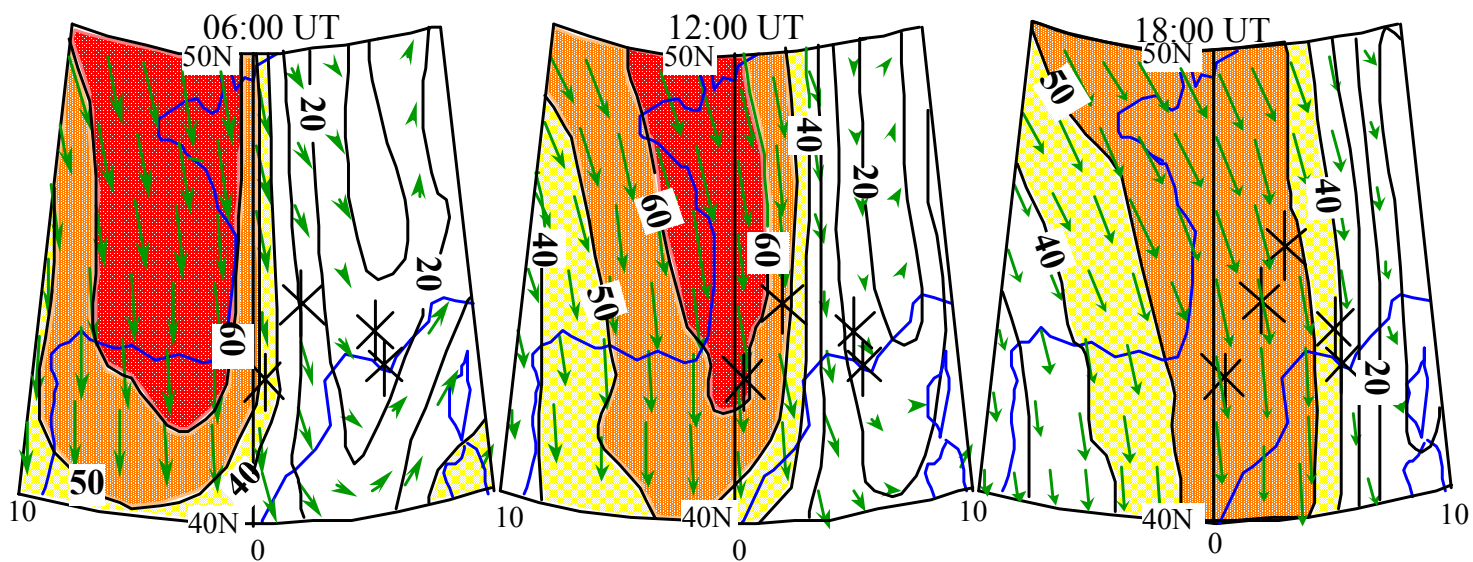

Fig. 2. ECMWF Analysis. Wind field on the $300 \mathrm{hPa}$ isobaric surface, on 4 March 1995 at 0600 (left); 1200 (center) and 1800 UTC (right). The four stars indicate the geographical location of the radars.
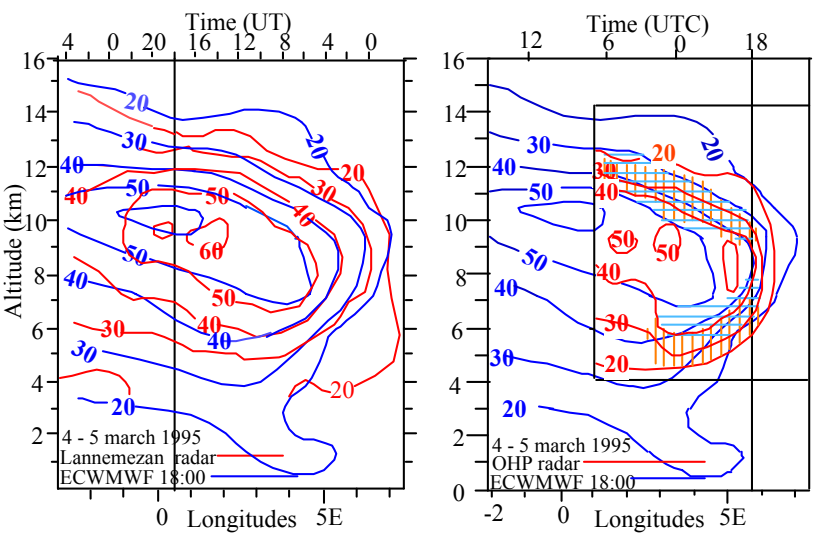

Fig. 3. (Left): Comparison of the meridional wind field measured on 4 March 1995 by the Lannemezan radar with the ECMWF meridional wind field in a west-east vertical cross section containing the radar site for the same day at 1800 UTC. (Right): Same comparison with the wind field measured by the OHP radar. The horizontal (blue) and vertical (red) lines indicate the region where the wind shears $\mathrm{S}$ are greater than $10^{-2} \mathrm{~m}^{-1}$ in the ECMWF model and for the observed wind field, respectively.

sociated with the jet stream is expected to cause a folding of the tropopause at the western flank of the trough. During its eastward advection, the wind field associated with the jet stream, which is supplied by the European model (ECMWF), is shown in Fig. 2. One might notice that although the jetstream is advected with the same velocity as the $P V$ anomaly, its intensity decreases after 1800 UTC, so that it cannot be said that the wind is a frozen field over the whole day. However, it will be seen in the following section that the wind shears generated by the jet stream may be considered as a frozen field.

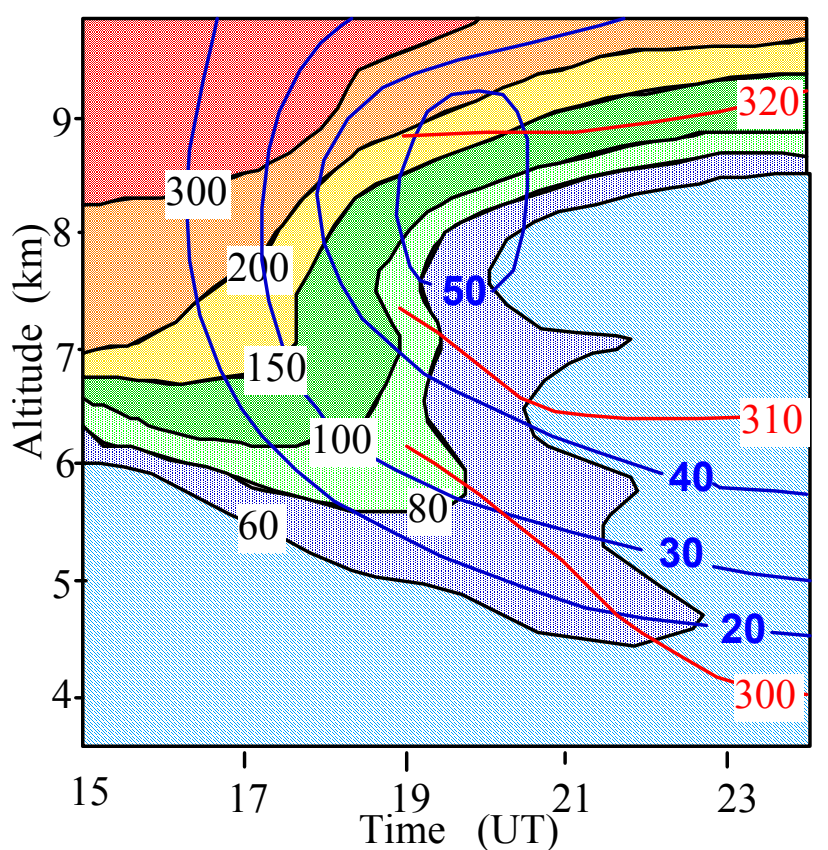

Fig. 4. Ozone mixing ratio (ppb) averaged over 10 minutes. Also drawn, three isentropes $(300,310$ and $320 \mathrm{~K})$ derived from the Raman lidar measurements and the observed wind field.

\subsection{Comparison of the wind observations with models}

In Fig. 3, the wind field derived from the ECMWF model output at 1800 UT is compared with the wind observations performed at Lannemezan and OHP radar (the western and eastern radar of the network, respectively).

In order to perform this comparison between ECMWF model and observations, the time coordinate of the radar cross section has been inverted (time is running from right to left), and converted into longitude by assuming a pure frozen eastward advection of the wind field with an average velocity of $30 \mathrm{~km}$ per hour. The black vertical lines positioned at 1800 

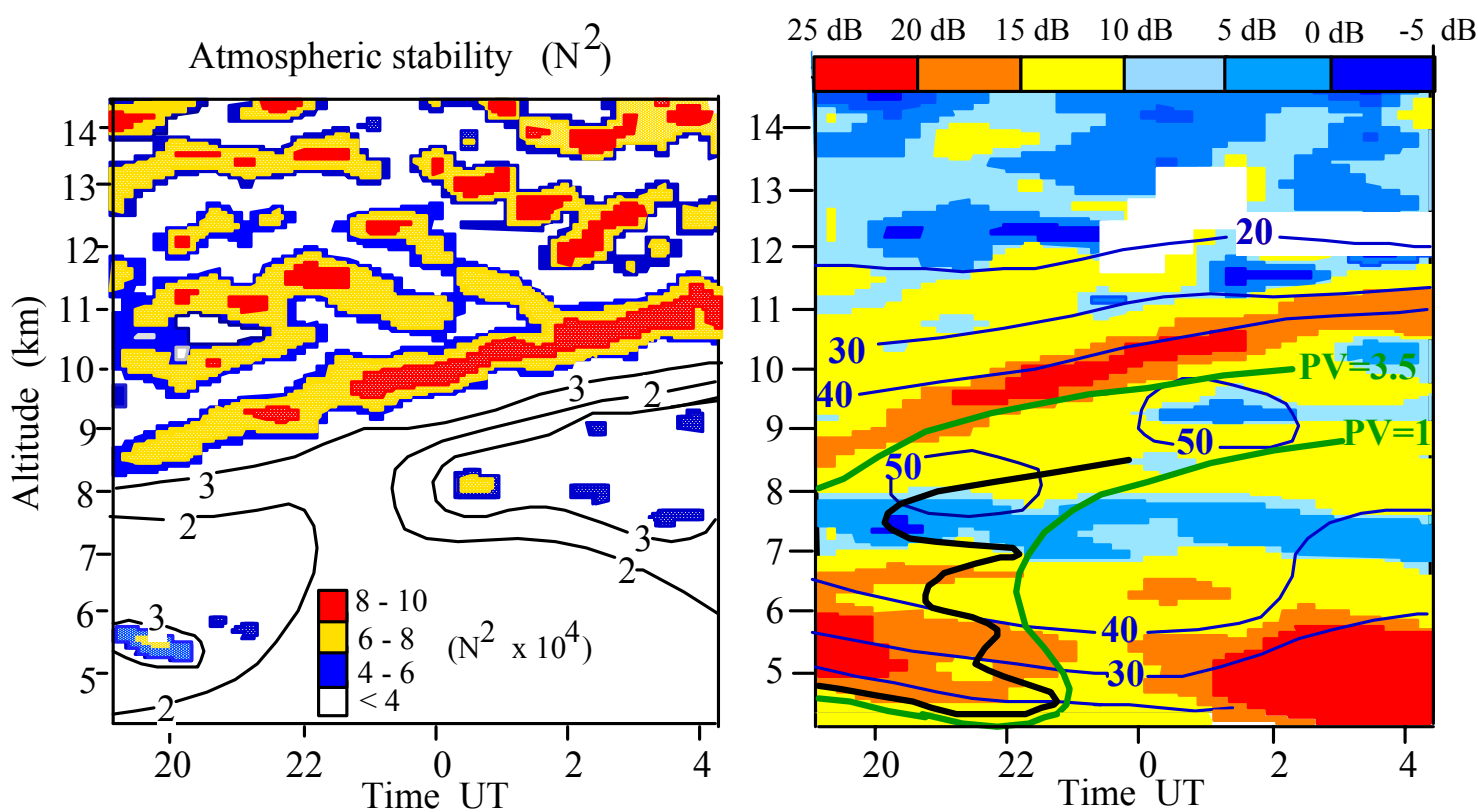

Fig. 5. Time-height cross section of: (a) the atmospheric stability $N^{2}\left(\mathrm{~s}^{-2}\right)$ deduced from the temperature field measured by the OHP Raman lidar, and (b) the signal-to-noise ratio (in $\mathrm{dB}$ ) measured along the vertical by the OHP VHF radar. Also drawn for comparison is the observed wind field (in blue), the $60 \mathrm{ppm}$ ozone iso-line, measured by the ozone lidar (in black), and in green, the potential vorticity iso- lines $P V=1$ (as a tracer of the fold) and $P V=3.5 \cdot 10^{-6} \mathrm{~m}^{2} \mathrm{~s}^{-1} \mathrm{~K} \mathrm{~kg}^{-1}$ (as a tracer of the thermal tropopause) deducted from the ECMWF model.

UT indicate the longitude of both radars (Lannemezan and OHP). The wind intensities measured at 1800 UT by the Lannemezan and OHP radar along these vertical lines are closely related to the ECMWF wind intensities at the same time and same longitude. For the other longitudes a good agreement between measured and ECMWF model wind fields may be noticed at Lannemezan, confirming the validity of the "frozen field" hypothesis before 1800 UT on 4 March 1995. For the OHP radar, a quasi uniform decrease of the wind field intensity of about $10 \mathrm{~m} / \mathrm{s}$ is observed after 1800 UT. However, this decrease does not significantly change the value of the observed wind shears, which are found to be quasi comparable with the model's wind shears.

As a conclusion, these comparisons confirm the validity of the frozen field approximation for the wind field observed on 4 March, before 1800 UT, while the wind shears may be considered as a frozen field up to 0600 UT on 5 March. So the observations do at two different sites in the network may be directly compared, under the above limitations, when the corresponding time shifts are taken into account. Moreover, the good agreement between measured and model simulated wind fields and/or wind shears allows us to use the model results (wind, temperature, stability, $P V$ fields) within the temporal limits defined above, in order to improve the analysis of the results obtained by the radars and lidars of the network.

2.2 Definition of a time relative to the fold and estimate of the time shifts

As the wind field is eastward advected without major deformation up to $1800 \mathrm{UT}$ on $4 \mathrm{March}$, the isotach $40 \mathrm{~m} / \mathrm{s}$ suc- cessively crosses over each radar of the network at time $T_{0}$, given in the last column of the Table 1 . The time $T_{0}$ will be taken as the reference time relative to the anomaly observed by each radar. Under the "frozen fields" hypothesis, the structures generated by the anomaly will be observed by the radars and lidars at the same relative time with respect to $T_{0}$. The corresponding times shifts are easily estimated from the knowledge of $T_{0}$ for each site.

\section{Detection of the tropopause folding}

\subsection{Detection by the ozone lidar}

The passage of the tropopause folding above the Haute Provence Observatory is observed on 4 March between 16:30 and 24:00 UTC, as shown in the Fig. 4, where the ozone mixing ratio measured by the ozone lidar exhibits the presence of a downward tongue of high mixing ratio values, whose altitude decreases as a function of time. It must be noted that the upper level frontal zone roughly follows the lower border of the ozone tongue (iso mixing ratio $\mathrm{O}_{3}=60 \mathrm{ppm}$ ). Also in the same figure are three isentropes, 300, 310 and $320 \mathrm{~K}$, derived from the temperature measurement obtained by the Raman lidar, and the wind field observed by the OHP radar.

Within the fold, the ozone mixing ratio is higher than in the troposphere, but lower than in the stratosphere, suggesting that mixing processes have already occurred. Quasi horizontal expansions of this tongue along the isentropes 300, 305 and $312 \mathrm{~K}$ are observed, and might be the signature, as suggested by Danielsen et al. (1991), of irreversible transport 
of stratospheric air masses along the isentropes by saturated internal gravity waves of short vertical wavelength. We shall see in Sect. 5 that generation of such unstable waves by the jet stream is possible.

\subsection{Detection by the OHP VHF ST radar and Raman lidar}

The atmospheric stability structures (squared values of the Brunt Vaisala frequency), observed by the Raman lidar at the Haute Provence Observatory, are shown in Fig. 5a, while the vertical signal-to-noise ratio, observed by the OHP VHF radar, is given in Fig. 5b. In Fig. 5a, the contours for $N^{2}=2$ and $3 \cdot 10^{-4} \mathrm{~s}^{-2}$ are drawn (in black), while in Fig. 5b, the observed wind field, the $60 \mathrm{ppm}$ ozone iso-line, and the potential vorticity iso-lines $P V=1$ and $P V=3.5 \cdot 10^{-6} \mathrm{~m}^{2} \mathrm{~s}^{-1}$ $\mathrm{K} \mathrm{kg}^{-1}$, deduced from the ECMWF model are drawn. It may be recalled that the iso-line $P V=3.5$ is often considered as a good tracer of the thermal tropopause (Hoerling et al., 1991; Ovarlez et al., 1999). It may be noted in Fig. 5b that the wind shear regions associated with the jet stream (observed in the altitude ranges $5-7 \mathrm{~km}$ and 9-11 km) exhibit maxima in the vertical signal-to-noise ratio, while stability maxima in Fig. 5a are primarily observed in the upper wind shears, above the thermal tropopause.

A good correlation is found between the shape of the $P V=$ 1 iso-line and the lower limit of ozone tongue structure observed by the ozone lidar (Fig. 4) and drawn for comparison in Fig. 5b. This correlation has already been noted and analyzed by Ravetta et al. (1999), and previously by Langford et al., 1996 and by Beeckmann et al., 1994. By virtue of the impermeability theorems for potential vorticity proposed by Haynes and McIntyre, (1990), only turbulence may transport stratospheric air particles from the fold across the $P V=1$ surface. As a matter of fact, in this region, maxima of the radar response are primarily caused by the turbulent activity, and are locally enhanced by partial reflection mechanisms. Turbulence is observed within the fold along the wind shears and is found to straddle its anticyclonic edge. More precisely, three turbulent layers are observed to approximately follow the three quasi horizontal expansions of the fold along the isentropes 300, 305 and $312 \mathrm{~K}$, already shown in Fig. 4. The same region is found to exhibit maxima in the oblique radar response at OHP and Toulon sites, with $C_{n}^{2}$ values of the order of $10^{-16} \mathrm{~m}^{-2 / 3}$.

On the other hand, in the upper wind shear region (9$11 \mathrm{~km}$ altitude), just above the thermal tropopause, a tilted layer of strong signal-to-noise ratio is observed by the radar, whose altitude increases from $8.5 \mathrm{~km}$ at $1900 \mathrm{UT}$, to $11 \mathrm{~km}$ nine hours later, and is found to closely follow the iso-line $P V=3.5$. The same tilted layer is also observed by the $\mathrm{Ra}-$ man lidar in the same altitude range as a region of high atmospheric stability (Fig. 8a), with $N^{2}$ values close to $10^{-3} \mathrm{~s}^{-2}$ over altitude ranges of some hundred metres. This good correlation between high atmospheric stability and vertical echo power could be considered as possibly resulting from partial reflection mechanism, as remarked by many authors (e.g. Green and Gage, 1980; Gage et al., 1985; Tsuda et al., 1988;
Dalaudier et al., 1989, Chu et al., 1990; Luce et al., 1995). However, it must be noted that the same region is also observed by the OHP and Toulon radar as a zone of enhanced radar echo power in the oblique direction. Therefore, both partial reflection and 3D turbulence are probably observed in this region. Presence of turbulence in this upper wind shear region is confirmed when comparing these results with those obtained in the same region by the high resolution UHF PROUST radar, generally considered not sensitive to partial reflection mechanisms. This comparison is possible, as emphasized in Sect. 2 (Fig. 3), because the wind shears associated with the jet stream may be considered as a frozen field. This point is developed in Sect. 4 .

\subsection{Detection of the fold by the aspect sensitivity obtained from Toulon and Lannemezan VHF radar measure- ments}

The so-called aspect sensitivity, or aspect ratio $(A R)$ of VHF radar measurements is the vertical-to-oblique beamreturned power ratio. This quantity is related to the zenith angle dependence of the backscattered power and spectral width. Strong $A R$ are primarily found in the stratosphere, where the vertical echo power is enhanced by the specular reflection on stable layers (Gage and Green, 1978; Hocking et al., 1990; Woodman and Chu, 1989; Yoe et al., 1994). However, as noted by Röttger (1980), the presence in the same radar gate of both stable layers and strong isotropic turbulence may significantly decrease the $A R$. Nevertheless, the aspect ratio has been frequently used to monitor the frontal zones, tropopause foldings and cutoff lows (Larsen and Röttger, 1985; Fukao et al., 1989; Crochet et al., 1990; Neiman et al., 1992, Campistron et al., 1999). Caccia and Cammas (1998) propose a monitoring of the folds and cutoff lows, in which the air masses of stratospheric origin (with high static stability) are defined by $A R>3$. This method is used in Caccia et al. (2000) for analyzing three cooperative campaigns involving the French radar network and discriminate between stratospheric and tropospheric air masses.

The time-height cross sections of the aspect ratio obtained by the Toulon and Lannemezan radar on 4 March 1995, is shown in the Figs. 6a and 7a, while the ECMWF static stability $\left(N^{2}\right)$ in the same cross sections, are shown in Figs. $6 \mathrm{~b}$ and 7b. For comparison, the iso-line $P V=1 P V$ unit (derived from the ECMWF analysis), and the wind field (in $\mathrm{m} / \mathrm{s}$ ) observed by the Toulon and Lannemezan radar are also drawn. As already mentioned above and observed in Fig. 5b, the $P V=1$ iso-line is found to be a good tracer of the lower limit of the tropopause folding. It may also be easily verified, as mentioned in Sect. 2 (and in the last column of the Table 1), that a time shift of about 14 hours of the $P V=1$ iso-line, shown in Fig. 7b, leads to a rather good coincidence with the $P V=1$ iso-line, shown in Fig. $6 \mathrm{~b}$, thus confirming the frozen field hypothesis for the $P V$ structures.

The $A R>3$ region, appearing in Figs. 6a and 7a, whose altitude decreases as a function of the time, is observed after the passage of the fold, and extends beyond its lower limit. 

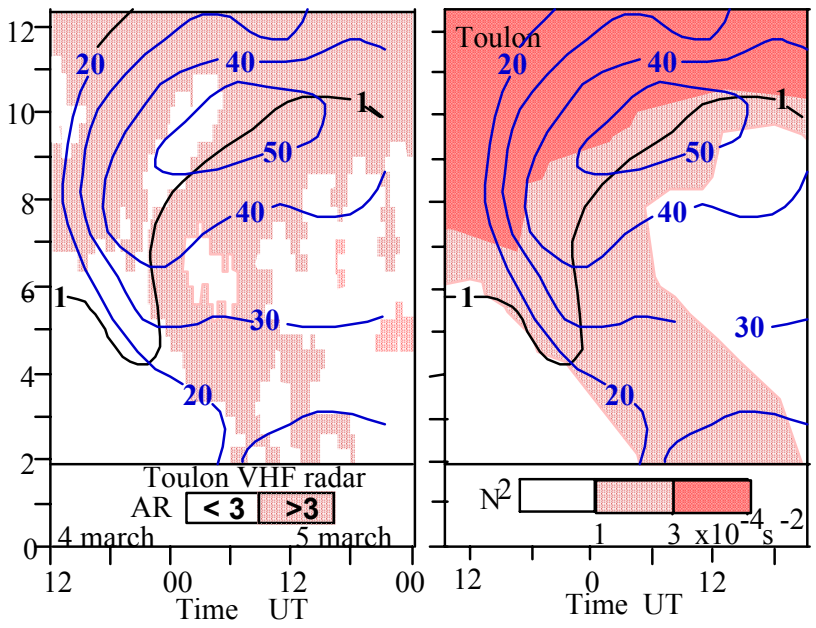

Fig. 6. Time-height cross section of (a) the Toulon VHF radar aspect ratio $(A R)$ and (b) the ECMWF model static stability on 4 and 5 March 1995. Also drawn in (a) and (b) is the wind field (in $\mathrm{m} / \mathrm{s}$ ), observed by the Toulon radar, and the potential vorticity iso-line $P V=1 P V$ units (black line), deducted from the ECMWF model analysis which has been found (in Fig. 5) to be a good tracer of the fold.

The stratospheric air within the fold is not detected by the aspect ratio method because its value is weakened in this region by the turbulence, as observed in Fig. 5. Another highly turbulent region is observed (Fig. 6a) in the upper level wind shears (along the isotachs $40-50 \mathrm{~m} / \mathrm{s}$ ) between 20 UT on March 4, and 06 UT on 5 March, and also leads to a strong decrease of the aspect ratio. This region corresponds well to the tilted layer observed just above the thermal tropopause on the OHP radar and lidar responses (Fig. 5a and 5b). On the other hand, the " $A R>3$ tongue", observed on the anticyclonic side of the fold, is well correlated with the ECMWF static stability $\left(N^{2}\right)$ model shown in Figs. 6b and 7b. In these last figures, the $P V=1$ potential vorticity iso-line, deduced from the ECMWF model, is also drawn as a tracer of the fold.

When analyzing these results, it appears that the stratospheric air masses, rich in ozone, are confined (as seen in Fig. 4) within the area delimited by the iso-line $P V=1$. On the outside of this limit, the ozone mixing ratio is close to tropospheric climatological values. However, $A R>3$ regions observed in the Figs. 6a and 7a, after the passage of the fold and below the jet stream axis, are the signature of air masses of stratospheric origin, also observed in Figs. $6 \mathrm{~b}$ and $7 \mathrm{~b}$, as region of high atmospheric stability. In order to solve this apparent contradiction, one could be tentatively supposed that these regions of potential vorticity smaller than unity have been included within the troposphere by diabatic processes (Lamarque and Hess, 1994). In this region, ozone and potential vorticity are progressively destroyed by latent heat release inside clouds, whose presence are apparently observed by the PROUST radar.

However, this hypothesis also implies that stratospheric air
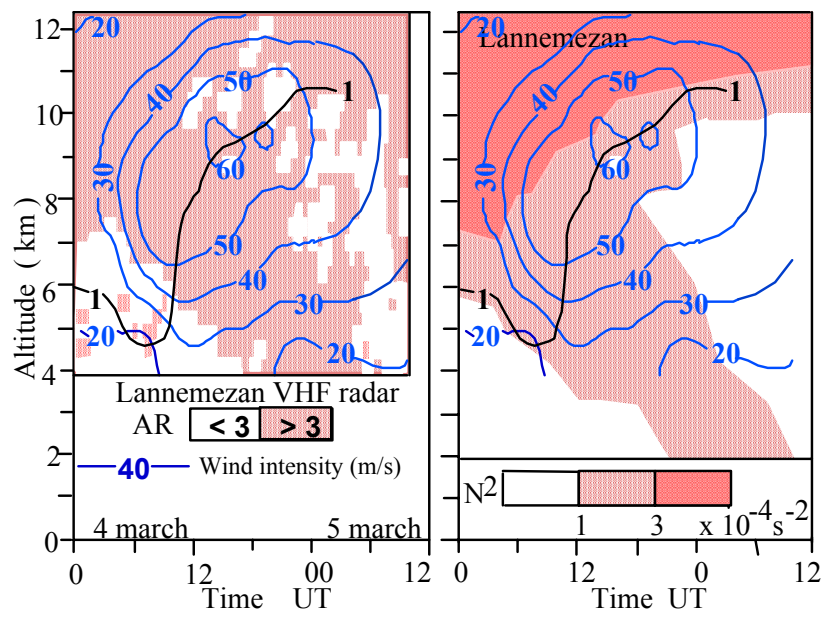

Fig. 7. Same as in Fig. 6, but for the Lannemezan radar. For comparison, the wind field measured by the Lannemezan radar and the iso-line $P V=1 \cdot 10^{-6} \mathrm{~m}^{2} \mathrm{~s}^{-1} \mathrm{~K} \mathrm{~kg}^{-1}$, deducted from the ECMWF model analysis are also drawn.

masses have been transferred into the troposphere through the $P V=1$ surface. As specified above, only the turbulence is able to give rise to such transfers. In Figs. 5b and $6 a$, the fold is observed to occur in a region where the wind shear $S$, generated by the jet stream, is locally greater than $2 \cdot 10^{-2} \mathrm{~s}^{-1}$. Taking into account the static stability $N^{2}$, which is given in the same region by the Raman lidar and the ECMWF model, it may be concluded that the Richardson number $R i=N^{2} / S^{2}$ is probably smaller than 0.25 within the fold: a condition for turbulence onset. The turbulent mixing thus occurring is generally considered as a mechanism for the exchange between the stratospheric and tropospheric air masses (Shapiro, 1980). The energy dissipation rate $\varepsilon$ and the vertical turbulent diffusivity $K_{z}$ have been tentatively estimated in this region from the $C_{n}^{2}$ values obtained by the Toulon radar measurements and knowledge of the static stability $N^{2}$ (Gage et al., 1980; Doviak and Zrnic, 1983; Bertin al., 1997; Dole and Wilson, 2000). When neglecting the humidity, $K_{z}$ values of approximately $K_{z}=0.1 \mathrm{~m}^{2} \mathrm{~s}^{-1}$ are found. Higher values $\left(0.3<K_{z}<1 \mathrm{~m}^{2} \mathrm{~s}^{-1}\right)$ have been obtained with the PROUST radar (see Sect. 4) in turbulent layers positioned just above the thermal tropopause. For an isotropic turbulence, the same values hold for the horizontal diffusivity $K_{y}$. Another possible transfer mechanism may also appear in wind shears regions: irreversible quasi horizontal transports induced by unstable inertia-gravity waves of short vertical wavelength (Danielsen, 1991). This mechanism has already been mentioned above, when analyzing the time-height cross section of the ozone mixing ratio (Fig. 4) as observed by the OHP ozone lidar. The decaying horizontal amplitude of such unstable waves and the generated turbulence might induce a horizontal diffusivity $K_{y}$ much higher than for the conventional 3D turbulence. Experimental in situ measurements on horizontal diffusion of aircraft exhaust plumes near the tropopause (Schumann et al., 1995) 


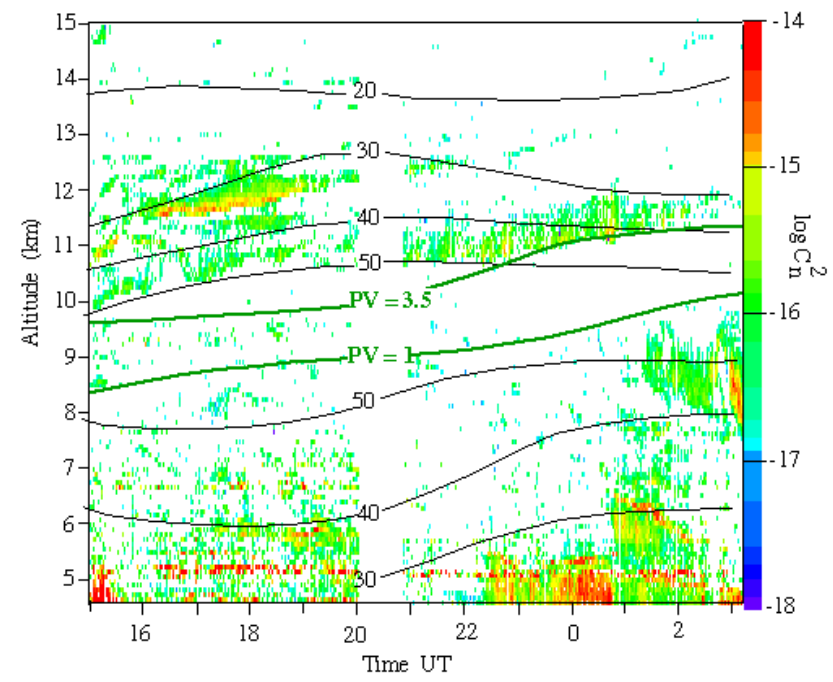

Fig. 8. Time-height cross section of the structure constant $C_{n}^{2}$ observed by the PROUST radar with a $30 \mathrm{~m}$ altitude resolution. Also drawn: the wind isotachs $(\mathrm{m} / \mathrm{s})$, and the iso-lines $P V=1$, giving the lower limit of the fold and $P V=3.5 \cdot 10^{-6} \mathrm{~m}^{2} \mathrm{~s}^{-1} \mathrm{~K} \mathrm{~kg}^{-1}$, often considered as a good indicator of the thermal tropopause. This additional information is derived from the ECMWF model. The lack of data between 20:00 and 20:45 UTC is due to an interruption of the radar transmitter.

have shown that $K_{y}$ could reach values of approximately 20 $\mathrm{m}^{2} \mathrm{~s}^{-1}$. However, the same study shows that the lateral dispersion of the plumes is weakly dependent on $K_{y}$ and is dominated by wind shears and vertical diffusivity. The lateral plume width has been found to grow with $\Delta y=\left(2 t K_{y}+\right.$ $\left.2 K_{z} S^{2} t^{3} / 3\right)^{1 / 2}$ (where $t$ is the time delay in seconds). When using this semi empirical formula, with the observed values of $S$, and with $K_{z}=0.1 \mathrm{~m}^{2} \mathrm{~s}^{-1}$, a lateral expansion $\Delta y=50 \mathrm{~km}$ during a time interval of 12 hours is obtained, while $\Delta y=150 \mathrm{~km}$ is obtained with $K_{z}=1$. This last value seems to be in better agreement with the observed lateral expansion of the observed $A R>3$ region for about 12 hours after the passage of the fold over the radar sites (see Figs. 5a and $6 a)$.

\section{Turbulent field observed by the high resolution PROUST radar and comparison with the OHP lidar results}

The main interest of the frozen field hypothesis validation, presented in the first section, is to make possible the comparison between VHF radar and lidar observations of the fold (shown in Figs. 4 and 5) and the results obtained in the same wind shear regions by the high resolution UHF PROUST radar (30 $\mathrm{m}$ altitude resolution) observing along the vertical direction. More precisely, we shall try below to better understand the structure of the turbulent layers observed in the wind shears by using the frozen field hypothesis.

We must first answer the following question: are the partialspecular reflection mechanisms (also termed Fresnel reflec- tion) possible with the UHF PROUST radar, whose wavelength is $\lambda=0.3 \mathrm{~m}$ ? It is recalled that the Fresnel reflection is caused by vertical temperature gradients for scales of the order of half the radar wavelength, that have a horizontal dimension comparable to the first Fresnel radius, and are long lived. For the PROUST radar, the scale of temperature gradients allowing partial reflections should be of the order of $0.15 \mathrm{~m}$, with an horizontal expansion greater than $55 \mathrm{~m}$ (value of the first Fresnel zone radius at $10 \mathrm{~km}$ altitude). In situ temperature measurements in the troposphere and stratosphere (Dalaudier et al., 1994; Muschinski et al., 1998) show the presence of submeter temperature sheets, which could fulfill the first condition for providing partial reflection mechanisms with the PROUST UHF radar. However, high resolution balloon-born measurements, using several temperature sensors $1 \mathrm{~m}$ apart horizontally and vertically (Dalaudier et al., 1994), show that the lateral expansion of such small scale temperature gradients is of the order of a few meters and is generally not horizontal. Thus, the second conditon above mentioned for partial reflection onset seems not to be satisfied. We shall conclude that the PROUST radar only observes (at least in the stratosphere) the turbulent fluctuations of the refractive index of the atmosphere. However, in the troposphere, the contribution of the hydrometeor response (clouds, rains, drizzle, snow and hail) may become predominant at this frequency.

The time-height evolution of the structure constant $C_{n}^{2}$, observed by the PROUST radar, is shown in Fig. 8. Unfortunately, the radar measurements begin 6 hours after the fold appeared above the site. Only the end of the tropopause folding is observed, as indicated by the iso-line $P V=1$. In the same figure, vertical west-east cross section are also drawn: the wind field (in $\mathrm{m} / \mathrm{s}$ ) and the temporal evolution of the isopotential vorticity $P V=3.5 P V$ units (heavy green line), used as a tracer of the thermal tropopause (Hoerling et al., 1991; Ovarlez et al., 1999). These complementary data are derived from the ECMWF analysis.

In the stratosphere, parallel turbulent layers generally aligned along the isotachs are observed in the wind shear regions associated with the jet stream. The lower one is observed between the isotachs 40 and $50 \mathrm{~m} / \mathrm{s}$ and follows the iso $P V=3.5$, after midnight. Three other turbulent layers, separated by a vertical distance of about $600 \mathrm{~m}$, are observed above the lower one. After 2000 UT, the layers number 2 and 4 vanish. These layers have a thickness of the order of $100 \mathrm{~m}$ and are separated by non turbulent regions; however, some of them, the more active ones, have a thickness greater than $300 \mathrm{~m}$. Between 1800 UTC and midnight, the altitude of the thermal tropopause progressively increases about $1 \mathrm{~km}$ and is setup just below the lower turbulent layer. After 2100 UT, the mean value estimate of the energy dissipation rate associated with this turbulent layer, when using the $C_{n}^{2}$ method (Dole and Wilson, 2000), is approximately $\varepsilon=8 \cdot 10^{-4} \mathrm{~m}^{2} \mathrm{~s}^{-3}$, and the vertical diffusivity is found in the range of $0.5<K_{z}<1$ $\mathrm{m}^{2} \mathrm{~s}^{-1}$. Same values are obtained when using the semi spectral width shown in Fig. 9, and the method proposed by Weinstock (1981) and Hocking (1983). This turbulence is able 


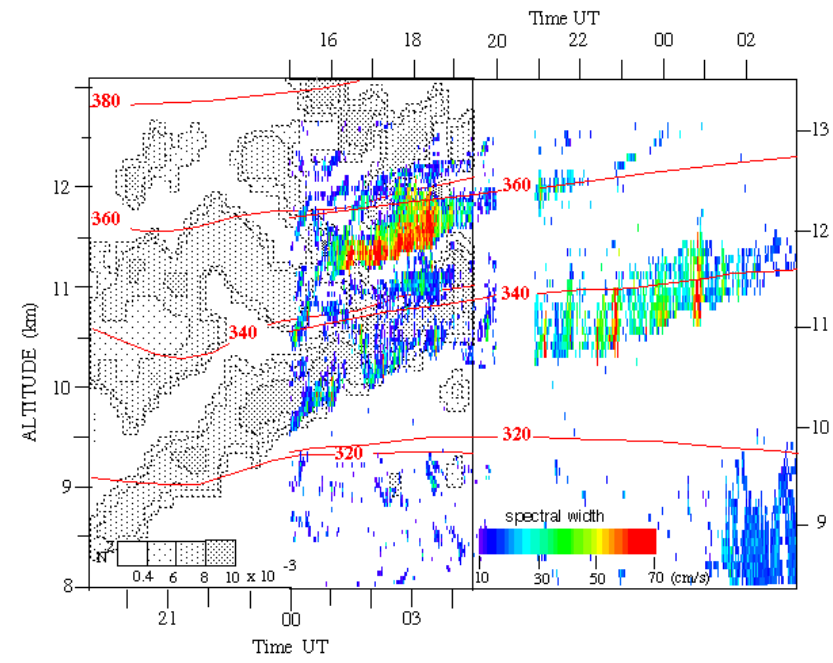

Fig. 9. Comparison of the turbulent field observed by the PROUST radar, with the stability structures detected by the Raman lidar. In order to take into account the advection of the fold, a time shift of 9 hours has been applied to the radar observations, while an altitude shift of about $0.5 \mathrm{~km}$ has been done in order to have the best possible continuity between the isentropes defined by the ECMWF model at Saint Santin and observed by the Raman lidar at OHP site.

to give rise to exchanges between the stratosphere (above the $P V=3.5$ iso-line) and the region edged by the $P V=1$ surface, which is connected to the fold, as shown in Fig. 5b.

In the troposphere (below the iso-line $P V=1$ ), the analysis is more complicated, since at the UHF PROUST radar frequency, clouds also give rise to radar echoes. Drizzle contribution (equivalent radar reflectivity of $0 \mathrm{dbZ}$ ) gives a $C_{n}^{2}$ of approximately $10^{-13} \mathrm{~m}^{-2 / 3}$, while cloud power return is observed to range between one and two orders of magnitude weaker. After midnight, radar echoes obtained below the $P V=1$ iso-line (with spectral width less than $0.2 \mathrm{~m} / \mathrm{s}$ and $C_{n}^{2}>10^{-15} \mathrm{~m}^{-2 / 3}$ ) could be the signatures of cirrus clouds. No convective activity (giving successive updraft and downdrafts) is observed in the troposphere during this time interval.

\subsection{Comparison with the OHP lidar results}

In order to make this comparison, a time shift of 9 hours must be done, corresponding to the advection time of the fold between both sites (see Table 1, last column). Under these conditions, the structures observed after 1500 UT at Saint Santin must be compared with those observed after 00 UT at the OHP site. In the upper troposphere and lower stratosphere, the air mass displacements follow the isentropes. Thus, when comparing the results obtained in both sites, it is of primary importance to emphasize the altitude continuity of the isentropes determined by the model or observation in each site. This continuity is roughly obtained by a downward vertical shift of approximately $0.5 \mathrm{~km}$ of the PROUST results. Taking into account these time and altitude shifts, it may be noticed that the turbulent layers observed by the PROUST radar

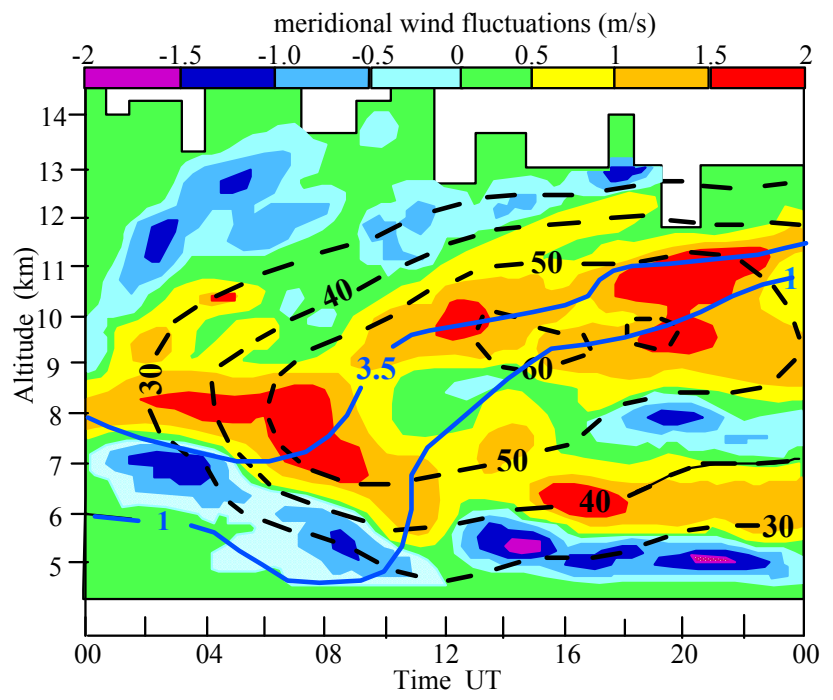

Fig. 10. Meridional wind fluctuations observed by the Lannemezan VHF radar. In the same cross section, the wind field (broken lines, in $\mathrm{m} / \mathrm{s}$ ), observed by the Lannemezan radar, and iso lines $P V=1$ and $P V=3.5 \cdot 10^{-6} \mathrm{~m}^{2} \mathrm{~s}^{-1} \mathrm{~K} \mathrm{~kg}^{-1}$, (blue lines) derived from the ECMWF analysis, are also shown.

above the thermal tropopause are parallel to the strongly stable region observed by the Raman lidar. A more careful comparison shows that the two lower turbulent layers are located on both sides of the main stable layer, in regions of weaker static stability, Thus, confirming that turbulence and partial reflection are met in this wind shear region.

The main information provided by this comparison is that both stable and turbulent layers are parallel to the wind isotachs. This particular configuration could be considered as the signature in this upper level wind shears of unstable inertia-gravity waves of short wavelength type, giving rise to both turbulent and stable layers. The same hypothesis has been already suggested in Sect. 3, when analysing the results obtained by the ozone lidar in the lower level wind shears. In order to test this hypothesis, it would be interesting to study the wind fluctuations in the wind shear regions over a time interval of at least 36 hours. Such a dataset is available from the results obtained by the Lannemezan radar. Therefore, applying the frozen field hypothesis for the wind field, the wind fluctuations observed by the Lannemezan radar are compared, in what follows, with the turbulent field observed by the PROUST radar.

\section{Analysis of the wind fluctuations observed by the Lan- nemezan radar, and comparison with the turbulent field observed by the PROUST and OHP radars}

Figure 10 shows the structures of the meridional wind perturbations observed by the Lannemezan radar. These structures have been obtained after a high pass filtering on each vertical profile, followed by a low pass temporal filtering. Also shown in the same figure is the wind field (black bro- 
ken lines), as observed by the Lannemezan radar, and the iso-lines $P V=1$ and 3.5 $P V$ units, as tracers of the fold and thermal tropopause, respectively. Oblique contours of wind perturbations are observed in the wind shear regions associated with the jet stream. They correspond to equi-phase lines (or lines of constant intensity) of the wind fluctuations. The altitude of these contours decreases as a function of the time below the jet stream axis and increases above it.

Several observations already reported in the literature in jet stream situations show such structures of wind fluctuations quasi aligned along the jet stream isotachs (Kilburn et al., 1995; Chilson et al., 1997; Thomas et al., 1999; Bertin et al., 1999). In all cases, the altitude of these structures increases above and decreases below the jet stream axis. In the case of the observation reported by Thomas et al., the authors explain the structure formed by the equi-phase lines by the presence of gravity waves propagating in the same direction as the jet stream, with an energy transported downwards in the troposphere and upwards in the stratosphere. The vertical wavelength and period of these waves was approximately $3 \mathrm{~km}$ and 10 hours, respectively.

In the present analyzed case, shown in Fig. 10, the same type of analysis (construction of hodographs of the perturbated velocity based on the mean values of meridional and zonal winds over 1 hour and $360 \mathrm{~m}$ altitude range) indicates the presence of an inertia-gravity wave of approximately 7 hours and $4 \mathrm{~km}$ in vertical wavelength. It may be noted that the equi-phase contours $\delta v=+1.5 \mathrm{~m} / \mathrm{s}$ and $\delta v=-1.5$ $\mathrm{m} / \mathrm{s}$ are both observed within the fold (defined by $P V=1$ ), along the isotachs 30 and $50 \mathrm{~m} / \mathrm{s}$, respectively. In the wind shear situated above the jet stream axis, the equi-phase contours $\delta v=+1 \mathrm{~m} / \mathrm{s}$ and $\delta v=-1 \mathrm{~m} / \mathrm{s}$ are also observed between the isotachs 30 and $40 \mathrm{~m} / \mathrm{s}$, respectively. These observations are in good accordance with the turbulent layers detected in the same lower and upper wind shear regions by the OHP and PROUST radars, when the corresponding time shift (due to the $P V$ anomaly advection) is taken into account. This good correlation is compatible with the presence of an inertia-gravity wave in this region.

\section{Concluding remarks}

The coordinated campaign presently analyzed was devoted to the study of the air mass exchange between the troposphere and the stratosphere during a tropopause folding episode. This subject has been addressed by several authors during the last ten years through observations by ST radars (Nastrom et al., 1989; Bertin et al., 1995; Campistron et al., 1999), by the modeling of case studies (Ebel et al, 1991; Lamarque and Hess, 1994; Wirth, 1995), and through meteorological analysis, radiosonde data and satellite data (total ozone and cloud images) (Price and Vaughan, 1993; Ancellet et al., 1994). Tropopause folds are known as regions of vigorous mixing, especially in summer. The mixing at the tropopause level in a cutoff cyclone has been stressed in the observational work of Shapiro (1980) and Danielsen (1987), but is also expected

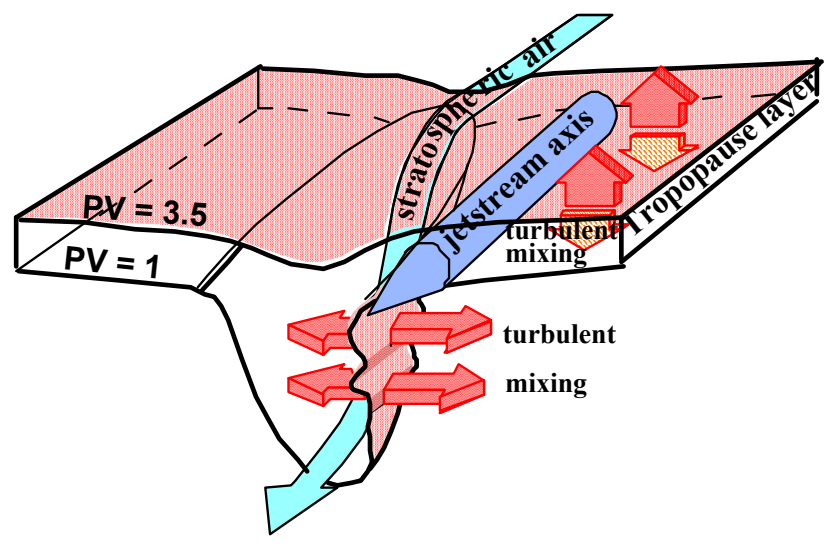

Fig. 11. Schematic representation of the mixing process observed by the radar and lidar network in the observed tropopause folding and in its vicinity. Turbulence regions (in red) occur in wind shear regions generated by the jet stream (i) within the fold and along its anticyclonic boundary, (ii) just above the thermal tropopause $(P V=$ $3.5 P V$ units).

at the bottom of a deep trough with high vorticity, if one follows the theoretical analysis of Hoskins and Bretherton (1972). According to Lamarque and Hess (1994), penetration of cumulonimbus anvils in the lower stratosphere, followed by radiative destabilization, may also be a significant mechanism for exchanging air between the troposphere and the stratosphere.

In case study presently analysed, no convective activity has been observed by the PROUST radar in the upper troposphere; however, the probable presence of cirrus clouds has been noticed after $T_{0}+10 \mathrm{~h}$. The observations performed by the operational network seem to confirm that the mixing processes between stratospheric and tropospheric air masses, during a tropopause folding episode, are closely associated with the wind shears generated by the jet stream. Regions of intense turbulent activity are observed in the lower and upper wind shears and are able to generate mixing between the fold, and the troposphere and the stratosphere, respectively. From these observations, the following scenario, summarized in Fig. 11, could be suggested:

1) The fold is continuously fed by air masses of stratospheric origin (blue-green arrow in Fig. 11), coming from the North along the trough formed by the $P V$ anomaly, shown in Fig. 1 (Danielsen et al., 1987), and continuously mixing with tropospheric air by a turbulent activity setup along its anticyclonic border ( $P V=1$ iso-line) due to strong wind shears occurring in this region (see Fig. 5);

2) Saturated internal gravity waves of short vertical wavelength, generated by the jet stream, might (as suggested by Danielsen et al., 1991) enhance the efficiency of the quasi horizontal turbulent transports along the isentropes (see Fig. 4);

3) Turbulent exchange between the stratosphere and the region (connected to the fold) stretching below the thermal tropopause $(P V=3.5)$ and bounded by the potential vorticity surface $P V=1$, are also induced by the turbulent activity 
observed in the upper level wind shears (just above the thermal tropopause) by the OHP radar (Fig. 5b) and the UHF PROUST radar (Fig. 8);

4) The dispersion within the troposphere of the air masses of stratospheric origin, transferred by the turbulence through the $P V=1$ surface within the troposphere, seems to be detected by the VHF radars aspect ratio. This dispersion is observed to spread over a large area (Figs. 6a and 7a), and seems to primarily depend on wind shears and vertical diffusivity intensities. Its efficiency could be estimated from the semi empirical equation proposed by Schumann et al., 1995.

Acknowledgements. The authors are very gratfull to Dr P. Van Velthoven from KNMI for providing us the ECMWF analysis needed for this study.

Topical Editor J. P. Duvel thanks K. Gage and M. Crochet for their help in evaluating this paper.

\section{References}

Ancellet, G., Beekmann, M., and Papayannis, A., Impact of a cutoff low development on downward transport of ozone in the troposphere, J. Geophys. Res., 99, 3451-3468, 1994.

Beeckmann, M., Ancelet, G., and Mégie, G., Climatology of tropospheic ozone in southern Europe and its relation to potential vorticity, J. Geophys. Res., 99, 12843-12853, 1994.

Bertin, F., Van Velthoven, P., Cremieu, A., Ney, R., and Beugin, R., UHF radar observation of strato-tropospheric transfers on the anticyclonic side of a jetstreak, Ann. Geophysicae, 13, 12291236, 1995.

Bertin, F., Barat, J., and Wilson, R., Energy dissipation ratesn eddy diffusivity and Prandt number: an in situ experimental approach and its consequences on radar estimate of turbulent parameters, Radio Sci., 32, 2, 791-804, 1997.

Bertin, F., Van Velthoven, P., Bessemoulin, P., Ney, R., and Massebeuf, M., Wave-turbulence interactions observed in the lower stratosphere by the PROUST UHF radar and GPS radiosoundings, J. Atmos. Terr. Phys., 61, 663-673, 1999.

Caccia, J. L. and Cammas, J. P., Radar observations of an upperlevel front using vertical and oblique-beam $C_{n}^{2}$ measurements, Monthly Weather Review, 126, 483-501, 1998.

Caccia, J. L., Bertin, F., Campistron, B., Klaus, V., Pointin, Y., van Baelen, J., and Wilson, R., Cut-off low monitoring by the French VHF-ST radar network during the ESTIME Campaign, J. Atmos. Terr. Phys., 62, 639-651, 2000.

Campistron, B., Pointin, Y., Lohou, F., and Pagès, J. P., Aspect sensitivity of VHF radar echoes observed in the middle and upper troposphere during the passage of a cut-off low, Radio Sci., 34, 667-680, 1999

Chilson, P. B., Muschinski, A., and Schmidt, G., Fist observations of Kelvin-Helmholtz billows in an upper level jet stream using VHF frequency domain interferometry, Radio Sci., 32, 3, 11491160, 1997.

Chu, Y. H., Chao, J. K., Liu, C. H., and Röttger, J., Aspect sensitivity at tropospheric heights measured with vertically pointed beam of the Chung-Li VHF radar, Radio Sci., 25, 539-550,1990.

Crochet, M., Cuq, F. Ralph,, F. M., and Venkateswaran, S. V., Clear air radar observations of the great October storm of 1987, Dynamics of the Atmosphere and Oceans, 14, 443-461, 1990.

Dalaudier, F., Sidi, C., Crochet, M., and Vernin, J., Direct evidence of "sheets" in the atmospheric temperature field, J. Atmos. Sci., 51, 237-248, 1994.

Danielsen, E. F., Hipskind, R. S., Gaines, S. E., Sachse, G. W., Gregory, G. L., and Hill, G. F., Three dimensional analysis of potential vorticity associated with tropopause folds and observed variations of ozone and carbon monoxide, J. Geophys. Res., 92, 2103-2111, 1987.

Danielsen, E. F., Hipskind, R. S., Starr, W. L., Vedder, J. F., Gaines, S. E., Kley, D., and Kelly, K. K., Irreversible transport in the stratosphere by internal waves of short vertical wavelength, J. Geophys. Res., 96, D9, 17433-17452, 1991.

Dole, J. and Wilson, R., Estimates of turbulent parameters in the lower stratosphere - upper troposphere by radar observations: A novel twist, Geophys. Res. Lett., 27, 2625-2628, 2000.

Doviak, R. J. and Zrnic', D. S., Reflection and scatter formula for anisotropically turbulent air, Radio Sci., 19, 1, 325-336, 1984.

Ebel, A., Hass, H., Jakobs, H., Laube, M., Memmesheimer, M., and Oberreuter, A., Simulation of ozone intrusion caused by a tropopause fold and cut-off low, Atmos. Envir., 25A, 2131-2144, 1991.

Fukao, S., Yamanaka, M. D., Matsumoto, H., Sato, T., Tsuda, T., and Kato, S., Wind fluctuations near a cold vortex-tropopause funnel system observed by the MU radar, Pure and Applied Geophysics, 130, 463-479, 1989.

Gage, K. S. and Green, J. L., Evidence for specular reflection from monostatic VHF radar observations of the stratosphere, Radio Sci., 13, 991-1001, 1978.

Gage, K. S. and Balsley, B. B., On the scattering and reflection mechanisms contributing to radar echoes, Radio Sci., 15, 243257, 1980.

Gage K. S., Ecklund, W. L., and Balsley, B. B., A model of Fresnel scattering for the parametrization of radar returns, Radio Sci., 20, 1493-1501, 1985.

Green, J. L. and Gage, K. S., Observations of stable layers in the troposphere and stratosphere using VHF radar, Radio Sci., 15, 395-405, 1980.

Haynes, P. H. and McIntyre, M. E., On the conservation and impermeability theorems for potential vorticity, J. Atmos Sci., 47 (16), 2021-2031, 1990.

Hocking, W. K., On the extraction of atmospheric turbulence parameters from radar backscatter Doppler spectra, J. Atmos. Terr. Phys., 45, 89-102, 1983.

Hocking, W. K., Fukao, S., Tsuda, T., Yamamoto, M., Sato, T., and Kato, S., Aspect sensitivity of stratospheric VHF radio wave scatters, particularly above $15 \mathrm{~km}$ altitude, Radio Sci., 25, 613 $627,1990$.

Hoerling, H. P., Schaack, T. K., and Lenzen, A. J., Global objective tropopause analysis, Mon. Weather Rev., 1816-1831, 1991. Hoskins, B. J. and Bretherton, F. P., Atmospheric frontogenesis models: mathematical formulation and solutions, J. Atmos. Sci., 29, 11-31, 1972.

Hoskins, B. J., McIntyre, M. E., and Robertson, A. W., On the use and significance of isentropic potential vorticity maps, Q. J. R. Meteorol. Soc., 111, 877-946, 1985.

Kilburn, C., Fukao, S., and Yamamoto, M., Extended period frequency domain interferometry observations at stratospheric and tropopsheric heights, Radio Sci., 30, 4, 1099-1109, 1995.

Lamarque, J. F. and Hess, P. G., Cross-tropopause mass exchange and potential vorticity budget in a simulated tropopause folding, J. Atmos. Sci., 51, 2246-2269, 1994.

Langford, A. O., Masters, C. D., Profit, M. H., Hsie, E. Y., and Tuck, A. F., Ozone measurements in a tropopause fold associated with 
a cut-off low system, Geophys. Res. Lett., 23 (18), 2501-2504, 1996.

Larsen, M. F. and Röttger, J., Observation of frontal zone and tropopause structure with a VHF radar and radiosondes, Radio. Sci, 20, 1223-1232, 1985.

Luce, H., Crochet, M., Dalaudier, F., and Sidi, C., Interpretation of VHF ST radar vertical echoes from in-situ temperature sheet observations, Radio Sci., 30, 4, 1003-1025, 1995.

Muschinski, A. and Wode, C., First in-situ evidence fo coexinting submeter temperature and humidity sheets in the lower free troposphere, J. Atmos. Sci., 55, 18, 2893-2906, 1998.

Nastrom, G. D., Green, J. L., Peterson, M. R., and Gage, K. S., Tropopause folding and the variability of the tropopause height as seen by the Flatland VHF radar, J. Applied Meteorol., 28, 12, 1271-1281, 1989.

Neiman, P. J., May, P. T., and Shapiro, M. A., Radio acoustic sounding system (RASS) and wind profiler observations of lower and mid-tropospheric weather system, Monthly Weather Review, 120, 2298-2313, 1992.

Ovarlez, J., Van Velthoven, P., and Schlager, H., Water vapor measurements from the troposphere to the lowermost stratosphere: some signatures of troposphere - stratosphere exchanges, J. Geophys. Res., 104, D14, 16973-16978, 1999.

Price, J. D. and Vaughan, G., The potential for stratospheretroposphere exchange in cut-off low systems, Q. J. R. Met. Soc., 119, 343-365, 1993.

Ravetta, F., Ancellet, G., Kowol-Santen, J., Wilson, R., and Nedeljkovic, D., Ozone, temperature and wind field measurements in a tropopause fold: comparison with a mesoscale model simulation, Monthly Weather Review, 127, 2641-2653, 1999.
Röttger, J., Reflection and scattering of VHF radar signals from atmospheric refractivity structures, Radio Sci., 15, 259-276, 1980.

Shapiro, M. A, Turbulent mixing within tropopause fold as a mechanism for exchange of chemical constituents between the stratosphere and troposphere, J. Atmos. Sci., 37, 994-1004, 1980.

Shumann, U., Konopka, P., Baumann, R., Busen, R., Gerz, T. Schlager, H., Schulte, P., and Volkert, H., Estimate of diffusion parameters of aircraft exhaust plumes near the tropopause from nitric oxide and turbulence measurements, J. Geophys. Res., 100, D7, 14147-14162, 1995.

Thomas, L., Worthington, R. M., and McDonald, A. J., Inertiagravity waves in the troposphere and lower stratosphere associated with a jet stream exit region, Ann. Geophysicae, 17, 115$121,1999$.

Tsuda, T., May, P. T., Sato, T., and Fukao, S., Simultaneous observations of reflection echoes and refractive index gradient in the troposphere and lower stratosphere, Radio Sci., 23, 655-665, 1988.

Weinstock, J., Energy dissipation rates of turbulence in the stable free atmosphere, J. Atmos. Sci., 38, 880-883, 1981.

Wirth, V., Diabatic heating in an axisymetric cut-off cyclone and related stratosphere-troposphere exchange, Q. J. R. Met. Soc., 121, 127-142, 1995.

Woodman, R. F. and Chu, Y. H., Aspect sensitivity measurements of VHF backscatter made with the Chung-Li radar: Plausible mechanisms, Radio Sci., 24, 113-125, 1989.

Yoe, J. G., Czechowsky, P., Rüster, R., and Schmidt, G., Spatial variability of the aspect sensitivity of CHF radar echoes in the troposphere and lower stratosphere during jet stream passages, Ann. Geophysicae, 12, 733-745, 1994. 